\title{
Effect of Vitamin C on Antioxidants, Lipid Peroxidation, and GSH System in the Normal Guinea Pig Heart
}

\author{
C. Rojas, S. Cadenas, R. Pérez-Campo, \\ M. LÓPEZ-TORRES, and G. BARJA \\ Department of Animal Biology-II (Animal Physiology), \\ Faculty of Biology, Complutense University, \\ Madrid 28040, Spain
}

(Received April 8, 1994)

\begin{abstract}
Summary Male guinea pigs were fed during 5 weeks with diets differing only in vitamin $\mathrm{C}$ content: low $(33 \mathrm{mg} / \mathrm{kg}$ diet), medium (660 $\mathrm{mg} / \mathrm{kg})$, and high $(13,200 \mathrm{mg} / \mathrm{kg})$. Heart vitamin $\mathrm{C}$ was strongly dependent on dietary vitamin $C$ and heart vitamin $E$ showed a trend to increase as a function of the vitamin $\mathrm{C}$ level in the diet. The low vitamin $\mathrm{C}$ diet decreased body weight gain, food intake, and heart malondialdehyde without changing lipid peroxidation, whereas the high vitamin $\mathbf{C}$ increased oxidized glutathione and glutathione peroxidase and decreased body growth. A tendency to show higher levels of all the first-line antioxidants reduced glutathione, uric acid, superoxide dismutase, catalase, and glutathione peroxidase at extreme (high or low) dietary levels of vitamin $\mathrm{C}$ was observed. The guinea pig heart showed capacity for enzymatic but not for non-enzymatic in vitro lipid peroxidation. It is concluded that dietary vitamin $\mathrm{C}$ supplementation is able to increase the global antioxidant capacity of the heart tissue.

Key words vitamin C, ascorbate, guinea pig, heart, antioxidants, lipid peroxidation, vitamin $\mathrm{E}$, glutathione peroxidase, superoxide dismutase, uric acid, catalase, glutathione reductase, malondialdehyde
\end{abstract}

Tissue oxygen consumption is a continuous process needed to obtain metabolic energy. Nevertheless, during normal mitochondrial respiration a certain fraction of oxygen consumption gives rise to the generation of oxygen radicals which are known to oxidatively damage lipids, proteins, and DNA. A certain amount of oxidative damage is always present in the cell even at resting respiratory conditions. Data suggest that this oxidative damage favors the appearance of degenerative illnesses such as cancer (1), cardiovascular diseases (2), and the aging process (36 ). If this is true, increasing the tissue antioxidant capacity should be protective against the development of those conditions. In fact, the majority of epidemiological and longitudinal studies performed to date indicate that vitamin $\mathbf{C}$ decreases 
the incidence of cardiovascular diseases $(7,8)$ and cancer $(9,10)$.

Diet-controlled antioxidants such as vitamins $\mathrm{C}$ and $\mathrm{E}$ are ideal to easily and safely increase tissue antioxidant capacity. Antioxidant enzymes or GSH (which is under feedback cellular control) do not seem to be suitable for this purpose. Guinea pig is a usefull model for these studies since they are not capable-like human beings - to synthesize ascorbate. On the other hand, previous studies in both vertebrates $(5,6)$ and invertebrates $(4)$ have shown that cellular antioxidants are subject to homeostatic control: if the animals are exposed to an oxidative stress in vivo, they react with compensatory inductions of endogenous antioxidants. Thus, it is possible that the reverse situation also takes place: increasing the levels of vitamin $\mathbf{C}$ (an antioxidant) can promote a reactive depression of endogenous antioxidants. An optimum dose of dietary vitamin $\mathrm{C}$ should be that one capable of increasing tissue vitamin $\mathrm{C}$ to protect against peroxidation of cellular macromolecules without depressing other cellular antioxidants under the cell genetic machinery control. Thus, comprehensive studies simultaneously measuring all the main enzymatic and non-enzymatic antioxidants, as well as tissue peroxidation, at different levels of vitamin $\mathrm{C}$ supplementation are needed. To our knowledge, few studies have been performed using this approach, and no information is available for the guinea pig heart. Cardiac muscle seems to be a very interesting tissue for this kind of study. It has a high aerobic metabolism based on oxygen consumption in the mitochondria (one of the main producers of oxygen radicals in normal tissue). On the other hand, heart disease is one of the leading causes of early death in adult humans. Thus, the effect of chronic dietary supplementation of guinea pigs with very low, intermediate, or very high levels of vitamin $\mathrm{C}$ on heart superoxide dismutase (SOD), catalase (CAT), glutathione peroxidase (GPx), glutathione reductase (GR), oxidized (GSSG) and reduced glutathione (GSH), vitamin C, vitamin $\mathrm{E}$, uric acid, enzymatic and non-enzymatic lipid peroxidation, and malondialdehyde (MDA) was simultaneously studied.

\section{MATERIALS AND METHODS}

Animals and diets. Dunkin-Hartley male guinea pigs were obtained from Iffa-Creddo, Lyon, France. A basal vitamin C-deficient laboratory diet (U.A.R., France) containing $19.5 \%$ protein, $3.1 \%$ fat, $68 \%$ carbohydrates, and $4.4 \%$ non-nutritive bulk was used. The content of minerals and vitamins per kilogram of diet was: phosphorus, 6,791 mg; calcium, 9,450 mg; potassium, 6,700 mg; sodium, $1,900 \mathrm{mg}$; magnesium, 2,003 mg; manganese, $90.7 \mathrm{mg}$; iron, $252 \mathrm{mg}$; copper, 30.6 mg; zinc, $113.4 \mathrm{mg}$; cobalt, $1.61 \mathrm{mg}$; iodine, $0.9 \mathrm{mg}$; vitamin A 19,000 I.U.; vitamin $\mathrm{D}_{3}, 1,500 \mathrm{I} . \mathrm{U}$.; vitamin $\mathrm{D}_{2}, 1,150 \mathrm{I}$.U.; thiamine, $18.5 \mathrm{mg}$; riboflavin, $18 \mathrm{mg}$; pantothenic acid, $16.5 \mathrm{mg}$; pyridoxine, $3.15 \mathrm{mg}$; $\alpha$-tocopherol, $15 \mathrm{mg}$; menadione, $2.5 \mathrm{mg}$; niacin, $190 \mathrm{mg}$; folic acid, $0.5 \mathrm{mg}$; biotin, $0.04 \mathrm{mg}$; choline, $1,600 \mathrm{mg}$; and vitamin $B_{12}, 0.02 \mathrm{mg}$.

The diets with different vitamin $\mathrm{C}$ levels were obtained by adding low (group 
$\mathrm{L} ; 33 \mathrm{mg}$ ), medium (M; $660 \mathrm{mg})$, or high $(\mathrm{H} ; 13,200 \mathrm{mg}$ ) amounts of L-ascorbic acid $/ \mathrm{kg}$ of basal diet. The animals were maintained during 5 weeks in the three experimental diets and were caged inside aseptic air positive-pressure animal cabinets (A 130 SP, Flufrance, Cachan, France) equipped with an HEPA air filter (99.999\% for particles $>0.3 \mu \mathrm{m}$ ) at the inlet. At the end of the dietary regimen, the animals were sacrificed by decapitation and samples from the whole ventricles were immediately dissected and stored at $-25^{\circ} \mathrm{C}$.

Enzyme activities. Heart samples were homogenized in $50 \mathrm{~mm}$ phosphate buffer ( $\mathrm{pH}$ 7.4). SOD was measured after $24 \mathrm{~h}$ of dialysis by quantifying the inhibition by SOD of pyrogallol autoxidation at $420 \mathrm{~nm}$ (11). CAT was measured following $\mathrm{H}_{2} \mathrm{O}_{2}$ disappearance at $240 \mathrm{~nm}$ (12). GPx was measured following NADPH oxidation at $340 \mathrm{~nm}$ in the presence of excess GR, GSH, and cumene hydroperoxide (13). GR was assayed by following NADPH oxidation at $340 \mathrm{~nm}$ in the presence of GSSG (14). All the enzymatic reactions were performed at $25^{\circ} \mathrm{C}$.

Low molecular weight antioxidants. Heart samples were homogenized in 5\% trichloroacetic acid with $0.01 \mathrm{~N} \mathrm{HCl}$ and total glutathione was measured by the spectrophotometric recycling assay (15) in the presence of 5,5'-dithiobis (2-nitrobenzoic acid), NADPH, and GR at $412 \mathrm{~nm}$. GSSG was assayed by the same method after derivatization of GSH with $12.5 \mathrm{mM} N$-ethylmaleimide (NEM) followed by alkaline hydrolysis of NEM (16). GSH values were obtained after subtracting GSSG from total glutathione. Samples of heart tissue were homogenized in $50 \mathrm{~mm}$ perchloric acid for simultaneous analysis of ascorbic and uric acid by ion pair HPLC with UV detectioin at $280 \mathrm{~nm}$ (17). Vitamin E ( $\alpha$-tocopherol) was measured by HPLC (18) with UV detection at $292 \mathrm{~nm}$.

Lipid peroxidation. MDA was measured by ion-pair HPLC with UV detection at $267 \mathrm{~nm}$ (19). Peroxidation was stimulated in vitro by incubating supernatants of heart samples in two different systems: a) $0.4 \mathrm{mM}$ ascorbate and $0.05 \mathrm{mM}$ $\mathrm{FeSO}_{4}$ for $0,30,60$, and 90 min at $25^{\circ} \mathrm{C}$ (non-enzymatic peroxidation) or b) $0.2 \mathrm{mM}$ $\mathrm{FeSO}_{4}, 5 \mathrm{mM} \mathrm{ADP}$, and $1 \mathrm{mM}$ NADPH during $90 \mathrm{~min}$ at $25^{\circ} \mathrm{C}$ (enzymatic peroxidation). At the end of the incubation period the thiobarbituric and (TBA) assay was performed. TBA-reactive substances (TBARS) were measured spectrophotometrically by a method specially adapted to tissue extracts (20) and the results are expressed in MDA equivalents.

Statistical analysis. The data were subjected to one-way analysis of variance (ANOVA). After the ANOVA, the Fisher's least significant difference (LSD) test was used when necessary to analyze significance differences between paired groups. The 0.05 level was selected as the minimal statistical significance in all the analyses.

\section{RESULTS}

The three dietary groups were designed in order to obtain three different situations with regards to vitamin $\mathrm{C}$ supplementation. Animals in group L (low; 33 $\mathrm{mg}$ of vitamin $\mathrm{C} / \mathrm{kg}$ diet) showed a total lack of vitamin $\mathrm{C}$ in the heart (Fig. 1A). 

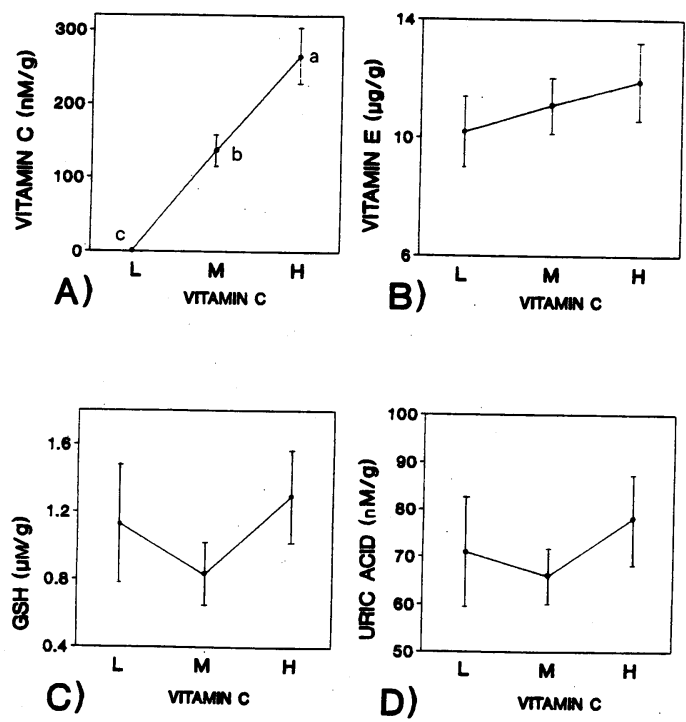

Fig. 1. Vitamin C, vitamin E, GSH, and uric acid concentration in heart tissue of guinea pigs treated during 5 weeks with diets having $33 \mathrm{mg}(\mathrm{L}), 660 \mathrm{mg}(\mathrm{M})$, or $13,200 \mathrm{mg}(\mathrm{H})$ of vitamin $\mathrm{C}$ per kilogram of basal diet. Differences between three groups were analyzed by Duncan's multiple range test: values without a common letter differ significantly $(p<0.05)$.

Thus, they can be considered vitamin $\mathrm{C}$ deficient from the point of view of this tissue, even though they ingested $0.5-1.1 \mathrm{mg}$ of vitamin $\mathrm{C}$ per day, which is similar to the minimum amount needed to avoid scurvy in guinea pigs. Group $M$ (medium) received $660 \mathrm{mg}$ of vitamin $\mathrm{C} / \mathrm{kg}$ diet. This is in the range used by most guinea pig commercial breeders which is considered optimum for growing and long-term maintenance of the animal. Group $\mathrm{H}$ (high, 13,200 mg of vitamin C/kg diet) was used to study the effects of a diet containing vitamin $\mathrm{C}$ levels much higher (about 20 times) than those present in standard guinea pig commercial diets.

The vitamin $\mathrm{C}$ content of the heart increased very significantly from group $\mathrm{L}$ to group $M$ and from group $M$ to group $H$ (Fig. 1A). Group $L$ showed total disappearance of vitamin $\mathbf{C}$ from cardiac tissue whereas group $\mathbf{H}$ showed vitamin $\mathbf{C}$ levels twice those of group $M$.

Animals in group L showed a decreased food intake (Table 1) in relation to the other two groups and body weight was maximum in group M. Animals receiving low or high amounts of vitamin $\mathrm{C}$ ( $\mathrm{L}$ and $\mathrm{H}$ groups) showed lower body growth in spite of the fact that body weight was similar, around $250 \mathrm{~g}$, in the three groups at the beginning of the experiment.

Even though no significant differences were found in heart vitamin $\mathrm{E}$ among the three groups, as seen in Fig. 1B, vitamin E levels tended to increase as vitamin $C$ levels increased. 
Table 1. Body weight and food intake of guinea pigs treated during 5 weeks with three diets differing in vitamin $\mathrm{C}$ levels.

\begin{tabular}{lccc}
\hline & \multicolumn{3}{c}{ Vitamin C group } \\
\cline { 2 - 4 } & $\mathrm{L}$ & $\mathrm{M}$ & $\mathrm{H}$ \\
\hline Body weight (g) & $282 \pm 19(6)^{\mathrm{b}}$ & $369 \pm 22(8)^{\mathrm{a}}$ & $294 \pm 15(7)^{\mathrm{b}}$ \\
Food intake (g) & $33.5 \pm 0.8(6)^{\mathrm{b}}$ & $44.8 \pm 1.8(8)^{\mathrm{a}}$ & $43.8 \pm 3.2(8)^{\mathrm{a}}$ \\
\hline
\end{tabular}

Values are $\mathbf{M} \pm$ SEM. Number of animals in parentheses. The content of vitamin $\mathrm{C}$ per kilogram of diet was $33 \mathrm{mg}$ (L, low), $660 \mathrm{mg}$ (M, medium), or $13,200 \mathrm{mg}(\mathrm{H}$, high). Differences between three groups were analyzed by Duncan's multiple range test: values without a common letter differ significantly $(p<0.05)$.
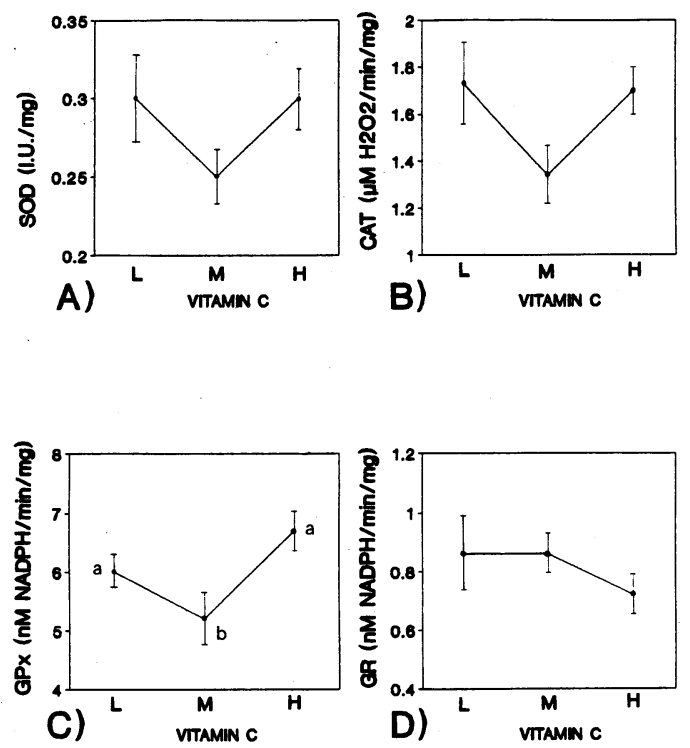

Fig. 2. Antioxidant enzymes in heart tissue of guinea pigs treated during 5 weeks with diets having $33 \mathrm{mg}(\mathrm{L}), 660 \mathrm{mg}(\mathrm{M})$, or $13,200 \mathrm{mg}(\mathrm{H})$ of vitamin $\mathrm{C}$ per kilogram of basal diet. Differences between three groups were analyzed by Duncan's multiple range test: values without a common letter differ significantly $(p<0.05)$.

The water-soluble antioxidants GSH, uric acid, SOD, and CAT did not show significant differences among vitamin $\mathrm{C}$ groups, but a trend to show minimum values in the intermediate $(M)$ group was systematically observed (Figs. 1C, D and 2A, B). This was reinforced by the same trend being present for GPx (Fig. 2C) which now showed a significantly higher value in group $\mathbf{H}$ than in group $\mathbf{M}$. This trend was not apparent in the case of GR (Fig. 2D), a secondary antioxidant enzyme which supplies the NADPH needed for GPx function. 
Table 2. Lipid peroxidation, GSSG, and GSH/GSSG in the heart of guinea pigs treated during 5 weeks with three diets differing in vitamin $\mathrm{C}$ levels.

\begin{tabular}{|c|c|c|c|}
\hline & \multicolumn{3}{|c|}{ Vitamin $\mathrm{C}$ group } \\
\hline & $\mathbf{L}$ & $\mathbf{M}$ & $\mathrm{H}$ \\
\hline $\operatorname{MDA}(\mathrm{nmol} / \mathrm{g}) 0 \mathrm{~min}$ & $3.1 \pm 0.6(5)^{b}$ & $6.5 \pm 1.1(7)^{\mathrm{a}}$ & $5.1 \pm 1.3(5)^{\mathrm{a}}$ \\
\hline $\begin{array}{l}\text { TBARS (ascorbate-Fe }{ }^{2+} \text { ) } \\
\text { (nmol MDA/g) } 0 \mathrm{~min}\end{array}$ & $59 \pm 14(5)$ & $51 \pm 11(8)$ & $52 \pm 9(7)$ \\
\hline $\begin{array}{l}\text { TBARS (ascorbate-Fe }{ }^{2+} \text { ) } \\
(\text { nmol MDA/g) } 30 \mathrm{~min}\end{array}$ & $51 \pm 22(4)$ & $77 \pm 17(8)$ & $52 \pm 30(4)$ \\
\hline $\begin{array}{l}\left.\text { TBARS (ascorbate-Fe }{ }^{2+}\right) \\
(\mathrm{nmol} \mathrm{MDA} / \mathrm{g}) 60 \mathrm{~min}\end{array}$ & $61 \pm 31(4)$ & $74 \pm 22(8)$ & $77 \pm 36(3)$ \\
\hline $\begin{array}{l}\text { TBARS (ascorbate- } \mathrm{Fe}^{2+} \text { ) } \\
(\mathrm{nmol} \mathrm{MDA} / \mathrm{g}) 90 \mathrm{~min}\end{array}$ & $64 \pm 26(4)$ & $62 \pm 16(8)$ & $50 \pm 27$ (4) \\
\hline $\begin{array}{l}\text { TBARS (NADPH-ADP-Fe }{ }^{2+} \text { ) } \\
(\mathrm{nmol} \mathrm{MDA} / \mathrm{g}) 90 \mathrm{~min}\end{array}$ & $215 \pm 26(4)$ & $208 \pm 18(8)$ & $249 \pm 34(5)$ \\
\hline GSSG $(\mu \mathrm{mol} / \mathrm{g})$ & $0.79 \pm 0.13(6)^{\mathrm{ab}}$ & $0.68 \pm 0.03(8)^{b}$ & $0.94 \pm 0.07(7)^{a}$ \\
\hline GSH/GSSG & $2.1 \pm 0.99$ & $1.3 \pm 0.33(8)$ & $1.4 \pm 0.32(7)$ \\
\hline
\end{tabular}

Values are $\mathbf{M} \pm$ SEM. Number of animals in parentheses. The content of vitamin $\mathbf{C}$ per kilogram of diet was $33 \mathrm{mg}$ (L, low), $660 \mathrm{mg}$ (M, medium), or 13,200 mg (H, high). The samples were incubated for $0,30,60$, or $90 \mathrm{~min}$ in the presence of ascorbate- $\mathrm{Fe}^{2+}$ or NADPH-ADP-Fe ${ }^{2+}$. Differences between three group were analyzed by Duncan's multiple range test: values without a common letter differ significantly $(p<0.05)$.

Significantly higher GSSG values were present in group $\mathbf{H}$ compared with group M (Table 2) even though the GSH/GSSG ratio did not change.

Endogenous levels of lipid peroxidation (TBARS at $0 \mathrm{~min}$, Table 2) were strongly and significantly higher when measured by the TBA test than when MDA was directly assayed by HPLC. Enzyme-dependent (NADPH-ADP-Fe ${ }^{2+}$ ) lipid peroxidation resulted in significantly higher TBA values than those obtained with ascorbate-Fe ${ }^{2+}$ (Table 2).

Comparison of TBARS (ascorbate-Fe ${ }^{2+}$ and NADPH-ADP-Fe ${ }^{+}$) among the three groups and of MDA between groups $M$ and $H$ did not result in significant differences in any case (Table 2).

\section{DISCUSSION}

The doses and times of vitamin $\mathrm{C}$ supplementation chosen were effective since heart vitamin $\mathrm{C}$ levels increased gradually from group $\mathrm{L}$ to group $\mathrm{H}$. Thus, heart vitamin $\mathrm{C}$ in the guinea pig is strongly dependent on the vitamin content of the diet.

The decrease in body growth in group $L$ is consistent with a previous report showing a decrease in body weight gain in guinea pigs receiving a diet totally deficient in vitamin $\mathrm{C}$ for 2 weeks, in relation to controls receiving $600 \mathrm{mg}$ of 
vitamin C per kilogram of diet (21).

Vitamin $\mathrm{E}$ levels tended to increase as vitamin $\mathrm{C}$ levels increased. This would be consistent with the proposed in vivo synergism between vitamins $\mathrm{C}$ and $\mathrm{E}$, already demonstrated in vitro (22). Vitamin $\mathrm{E}$ is the major lipid soluble antioxidant in cell membranes, where it can act as a chain breaking antioxidant reducing peroxyl (LOO•) and alkoxyl ( $\mathrm{LO} \cdot$ ) fatty acids to their corresponding products, lipid hydroperoxides (LOOH) and the stable lipid hydroxides (LOH). In this process, vitamin $\mathrm{E}$ is oxidized to the tocopheroxyl radical which is not capable of continuing the antioxidant function. Vitamin $\mathrm{E}$ levels in biological membranes are three orders of magnitude smaller than those of fatty acids. Thus, antioxidant function of vitamin $\mathrm{E}$ needs continuous reduction of tocopheroxyl radical back to vitamin $\mathrm{E}$, a task which can be performed by two antioxidants, vitamin C and GSH. The trend observed here of higher vitamin E levels at higher levels of vitamin $C$ can be caused by this synergism between both vitamins operating in vivo. A higher vitamin $E$ level in group $H$ than in group $M$ would also be consistent with the significantly higher levels of GPx in group $\mathrm{H}$, since this enzyme can reduce the lipid hydroperoxides (LOOH), formed by the chain breaking action of vitamin $\mathrm{E}$ on lipid peroxyl radicals (LOO•), to stable lipid hydroxides (LOH). The relatively low levels of oxidative stress expected in a resting intact animal can avoid a strong vitamin E consumption in vitamin C-deficien animals, thus explaining the lack of significant differences in vitamin $\mathrm{E}$ between the three groups.

It has been previously shown that ascorbate can have both antioxidant or prooxidant effects $(23,24)$ depending on a number of factors including ascorbate concentration and availability of transition metals. The systematic trend to show elevated levels of all the first line antioxidants both at low and high levels of ascorbate can be due to a mild oxidative stress being produced in vitamin Cdeficient or excessively supplemented heart tissue. The presence of this mild oxidative stress is also supported by the significantly higher GSSG values present in group $\mathrm{H}$ in relation to group $\mathrm{M}$ even though the GSH/GSSG ratio did not change. Negative effects of very high doses of vitamin C, similar to those used here have been described in other systems. Thus, in agreement with our results, growing of guinea pig offspring receiving $5,000 \mathrm{mg}$ of vitamin $\mathrm{C}$ per kilogram of diet is delayed (25). In addition, high doses of vitamin $C$ in man (5,000 $\mathrm{mg}$ per day or higher) can increase oxalate and uric acid excretion (26) and increase iron deposits in the liver $(21,25)$.

The higher values of lipid peroxidation when it was measured by the TBA test than when MDA was directly assayed by HPLC show that, in agreement with data from liver, lung, and brain from seven vertebrate species (27), the TBA assay measures other substances (related or not to lipid peroxidation) in addition to MDA in heart tissue. On the other hand, whereas incubation in the presence of ascorbate- $\mathrm{Fe}^{2+}$ (non-enzymatic lipid peroxidation) increases TBA values as a function of time in the guinea pig liver (28) and brain (29), this does not occur in the heart. Nevertheless, enzyme-dependent (NADPH-ADP-Fe ${ }^{2+}$ ) lipid peroxida- 
tion resulted in higher TBA values than those obtained with asccorbate- $\mathrm{Fe}^{2+}$. This suggests that the guinea pig heart possesses systems capable of transporting electrons from NADPH to iron, similarly to what occurs for various enzymes and cytochromes of the microsomal fraction in the liver membranes of various mammals.

The fact that a comparison of TBARS (ascorbate-Fe ${ }^{2+}$ and NADPH-ADP$\mathrm{Fe}^{2+}$ ) among the three groups and MDA between groups $\mathbf{M}$ and $\mathbf{H}$ revealed no significant differences shows that vitamin supplementation does not change lipid peroxidation in heart tissue in the intact animal under basal aerobic conditions. The paradoxically decreased MDA values (HPLC) observed in group $L$ do not imply the presence of a lower lipid peroxidation level in this group, since this result was not confirmed by enzymatic and non-enzymatic lipid peroxidation values. Lipid peroxidation is a complex process which gives rise to the production of many other substances, detected in the TBA test, in addition to MDA. These additional lipid peroxidation products are much more abundant than MDA in many peroxidation models (30). In addition, MDA is metabolized in mitochondria in a very poorly understood way. It is possible that vitamin $\mathrm{C}$ deficiency changed MDA catabolism without changing lipid peroxidation. The lack of changes in lipid peroxidation does not rule out the possibility that the higher vitamin $\mathrm{C}$ values of groups $\mathbf{M}$ and $\mathbf{H}$ are of protective value against any additional oxidative stress challenge in various physiological (e.g. exercise (31)) or pathological situations. The experiment described here was performed with intact animals under basal aerobic conditions. In this basal state, it is possible that the various components of the antioxidant system, different from vitamin $C$, are enough to counteract the small amounts of free radicals generated in the tissue. It is also possible that a mild oxidative stress in groups $\mathrm{H}$ and $\mathrm{L}$ does not give rise to increases in lipid peroxidation due to an induction of all the first-line antioxidants, as suggested from data obtained in this work. In any case, it can be concluded that dietary vitamin C supplementation over large ranges (400 times from group $\mathrm{L}$ to group $\mathrm{H}$ ) increases the global antioxidant capacity of the heart since it leads to higher vitamin $\mathrm{C}$ levels in the tissue without depressing any other cellular antioxidant by homeostatic compensation. This shows the utility of dietary vitamin $\mathrm{C}$ supplementation to increase the antioxidant defense of the heart. This increased protection can be essential when an additional oxidative challenge is imposed to the tissue.

This work was supported by a grant (No. 93/0145E) from the National Research Foundation of the Spanish Ministry of Health (FISss). Fellowships were received by $\mathbf{M}$. López-Torres and C. Rojas (F.P.I., Ministry of Education), S. Cadenas (Complutense University), and R. Pérez-Campo (FISss).

\section{REFERENCES}

1) Ames, B. N. (1989): Endogenous oxidative DNA damage, aging, and cancer. Free 
Rad. Res. Commun., 7, 121-128.

2) Frei, B. (1991): Ascorbic acid protects lipids in human plasma and low-density lipoprotein against oxidative damage. Am. J. Clin. Nutr., 54, 1113S-1118S.

3) Harman, D. (1956): Aging: a theory based on free radical and radiation chemistry. $J$. Gerontol., 11, 298-300.

4) Sohal, R. S., Farmer, K. J., Allen, R. G., and Ragland, S. S. (1984): Effects of diethyldithiocarbamate on lifespan, metabolic rate, superoxide dismutase, catalase, inorganic peroxides and glutathione in the adult male housefly, Musca domestica. Mech. Ageing Dev., 24, 175-183.

5) López-Torres, M., Pérez-Campo, R., Fernandez, A., Barba, C., and Barja de Quiroga, G. (1993): Brain glutathione reductase induction increases early survival and decreases lipofuscin accumulation in aging frogs. J. Neurosci. Res., 34, 233-242.

6) López-Torres, M., Pérez-Campo, R., Rojas, C., Cadenas, S., and Barja de Quiroga, G. (1993): Simultaneous induction of SOD, glutathione reductase, GSH and ascorbate in liver and kidney correlates with survival during aging. Free Rad. Biol. Med., 15, 133142.

7) Gaziano, J. M., Manson, J. E., Buring, J. E., and Hennekens C. H. (1992): Dietary antioxidants and cardiovascular disease. Ann. N.Y. Acad. Sci. U.S.A., 669, 249-259.

8) Simon, J. A. (1992): Vitamin C and cardiovascular disease: a review. J. Am. College Nutr., 11, 107-125.

9) Block, G. (1991): Epidemiologic evidence regarding vitamin C and cancer. Am. J. Clin. Nutr., 54, 1310S-1314S.

10) Byers, T., and Perry, G. (1992): .Dietary carotenes, vitamin C, and vitamin E as protective antioxidants in human cancers. Annu. Rev. Nutr., 12, 139-159.

11) Marklund, S., and Marklund, G. (1974): Involvement of the superoxide anion radical in the autoxidation of pyrogallol and a convenient assay for superoxide dismutase. Eur. J. Biochem., 47, 469-474.

12) Beers, R. F., and Sizer, W. I. (1952): A spectrophotometric method for measuring the breakdown of hydrogen peroxide by catalase. J. Biol. Chem., 195, 133-140.

13) Lawrence, R. A., and Burk, R. F. (1976): Glutathione peroxidase activity in selenium-deficient rat liver. Biochem. Biophys. Res. Commun., 71, 952-958.

14) Massey, V., and Williams, C. H. (1956): On the reaction mechanism of yeast glutathione reductase. J. Biol. Chem., 240, 4470-4481.

15) Tietze, F. (1969): Enzymic method for quantitative determination of nanogram amounts of total and oxidized glutathione: applications to mammalian blood and other tissues. Anal. Biochem., 27, 502-522.

16) Sachetta, P., Di Cola, D., and Federichi, G. (1986): Alkaline hydrolysis of $N$ ethylmaleimide allows a rapid assay of glutathione disulfide in biological samples. Anal. Biochem., 154, 205-208.

17) Barja de Quiroga, G., López-Torres, M., Pérez-Campo, R., and Rojas, C. (1991): Simultaneous determination of two antioxiddants, uric and ascorbic acid, in animal tissue by high-performance liquid chromatography. Anal. Biochem., 199, 81-85.

18) Vatassery, G. T., Brin, M. F., Fahn, S., Kayden, H. J., and Traber, M. G. (1988): Effect of high doses of dietary vitamin $E$ on the concentrations of vitamin $E$ in several brain regions, plasma, liver, and adipose tissue of rats. J. Neurochem., 51, 621-623.

19) Bull, A. W., and Marnett, L. J. (1985): Determination of malondialdehyde by 
ion-pairing high-performance liquid chromatography. Anal. Biochem., 149, 284-290.

20) Uchiyama, M., and Mihara, M. (1978): Determination of malonaldehyde precursor in tissues by thiobarbituric acid test. Anal. Biochem., 86, 271-278.

21) Saito, M., and Yamaguchi, M. (1988): Influence of excessive ascorbic acid dose on liver microsomal mixed function oxydase system in guinea pigs. J. Clin. Biochem. Nutr., 4, 123-137.

22) Packer, L., Slater, T. F., and Willson, R. L. (1979): Direct observation of a free radical interaction between vitamin $\mathrm{E}$ and vitamin C. Nature (Lond.), 278, 737-738.

23) Stadtman, E. R. (1991): Ascorbic acid and oxidative inactivation of proteins. Am. J. Clin. Nutr., 54, 1125S-1128S.

24) Kadiiska, M. B., Hanna, P. M., Hernandez, L., and Mason, R. P. (1992): In vivo evidence of hydroxyl radical formation after acute copper and ascorbic acid intake: Electron spin resonance spin-trapping investigation. Mol. Pharmacol., 42, 723-729.

25) Bates, C. J., Cowen, T. D., and Tsuchiya, H. (1988): Growth, ascorbic acid and iron contents of tissues of young guinea-pigs whose dams received high or low levels of dietary ascorbic acid or Fe during pregnancy and suckling. Br. J. Nutr., 60, 487-497.

26) Rivers, J. M. (1987): Safety of high-level vitamin C ingestion. Ann. N.Y. Acad. Sci., 498, 445-454.

27) López-Torres, M., Pérez-Campo, R., Cadenas, S., Rojas, C., and Barja, G. (1993): A comparative study of free radicals in vertebrates. II. Non-enzymatic antioxidants and oxidative stress. Comp. Biochem. Physiol., 105B, 757-763.

28) López-Torres, M., Pérez-Campo, R., Rojas, C., Cadenas, S., and Barja, G. (1993): Maximum life span in vertebrates: correlation with liver antioxidant enzymes, glutathione system, ascorbate, urate, sensitivity to peroxidation, true malondialdehyde, in vivo $\mathrm{H}_{2} \mathrm{O}_{2}$, and basal and maximum aerobic capacity. Mech. Ageing Dev., 70, 177-199.

29) Barja, G., Cadenas, S., Rojas, C., López-Torres, M., and Pérez-Campo, R. (1994): A decrease of free radical production near critical sites as the main cause of maximum longevity in animals. Comp. Biochem. Physiol., 108B, 501-512.

30) Halliwell, B., and Gutteridge, J. M. C. (1989): Lipid peroxidation: a radical chain reaction, in Free Radicals in Biology and Medicine, Clarendon Press, Oxford, pp. 188276.

31) Barja de Quiroga, G. (1992): Brown fat thermogenesis and exercise: two physiological examples of in vivo oxidative stress. Free Rad. Biol. Med., 13, 325-340. 